Case Report

\title{
Gastric Metastasis of Ectopic Breast Cancer Mimicking Axillary Metastasis of Primary Gastric Cancer
}

\author{
Selami Ilgaz Kayılığlu, ${ }^{1}$ Cihangir Akyol, ${ }^{2}$ Ebru Esen, ${ }^{3}$ Cevriye Cansız-Ersöz, ${ }^{4}$ \\ Akın Fırat Kocaay, ${ }^{2}$ Volkan Genç, ${ }^{2}$ Ilknur Kepenekçi, ${ }^{2}$ and Seher Demirer ${ }^{2}$ \\ ${ }^{1}$ Department of General Surgery, Ankara Numune Research and Training Hospital, 06100 Ankara, Turkey \\ ${ }^{2}$ Department of General Surgery, Ankara University School of Medicine, 06100 Ankara, Turkey \\ ${ }^{3}$ Department of Surgical Oncology, Ankara University School of Medicine, 06590 Ankara, Turkey \\ ${ }^{4}$ Department of Medical Pathology, Ankara University School of Medicine, 06100 Ankara, Turkey \\ Correspondence should be addressed to Selami Ilgaz Kayılığlu; kayilioglu@yahoo.com
}

Received 16 October 2014; Accepted 29 November 2014; Published 11 December 2014

Academic Editor: Haruhiko Sugimura

Copyright ( 2014 Selami Ilgaz Kayllığlu et al. This is an open access article distributed under the Creative Commons Attribution License, which permits unrestricted use, distribution, and reproduction in any medium, provided the original work is properly cited.

\begin{abstract}
Ectopic breast tissue has the ability to undergo all the pathological changes of the normal breast, including breast cancer. Gastrointestinal metastasis of breast cancer is rarely observed and it is very difficult to differentiate gastric metastases from primary gastric cancer. We present a case of 52-year-old female, who suffered from abdominal pain. Physical examination showed a palpable mass in the left anterior axilla and computerized tomography revealed gastric wall thickening with linitis plastica. When gastroscopic biopsy showed no signs of malignancy, excisional biopsy was performed in the left axilla. Histological examination revealed invasive lobular carcinoma of the breast, consistent with ectopic breast cancer. Further gastroscopic submucosal biopsies and immunohistochemical studies revealed gastric metastases of invasive lobular carcinoma. Axillary ectopic breast tissue carcinomas can mimic axillary lymphadenopathies. Additionally, gastric metastasis of breast cancer is an uncommon but possible condition. To the best of our knowledge, this is the first report of ectopic breast cancer with gastric metastasis.
\end{abstract}

\section{Introduction}

Ectopic breast tissue may be observed in any site along the milk line, from the axilla to the inguinal region $[1,2]$. Although the incidence of ectopic breast tissue is not clearly known, it is believed to be $1 \%$ in the general population [1]. Ectopic breast tissue has the ability to undergo all the pathological changes of the normal breast, including breast cancer. Carcinoma occurs more frequently in ectopic breast tissue occurring in the axilla than in extra-axillary ectopic breast tissue. Local and distant metastases of breast cancer to the lymph node, bone, pulmonary, liver, and brain are frequently seen. Gastrointestinal metastases are rarely observed [3] and when a malignant lesion is detected in the stomach, it is very difficult to differentiate gastric metastasis of breast cancer from primary gastric cancer clinically, endoscopically, radiologically, and pathologically. Some of these patients undergo gastrectomy, with a preoperative diagnosis of primary gastric cancer. As gastric metastasis of breast cancer is rarely encountered, literature review failed to demonstrate gastric metastases of cancer originating from ectopic breast tissue.

\section{Case Presentation}

A 52-year-old female patient presented with abdominal pain and weight loss for 6 months. On physical examination, mobile mass measuring $3 \times 2.5 \times 1 \mathrm{~cm}$ with smooth margins was palpated in the left anterior axillary line. Gastric wall thickening with linitis plastica appearance was detected on computerized tomography (Figure 1). Upper gastrointestinal system endoscopy showed atrophic mucosal changes in the stomach, and histological examination did not show any malignant cells. With a preoperative diagnosis of axillary 


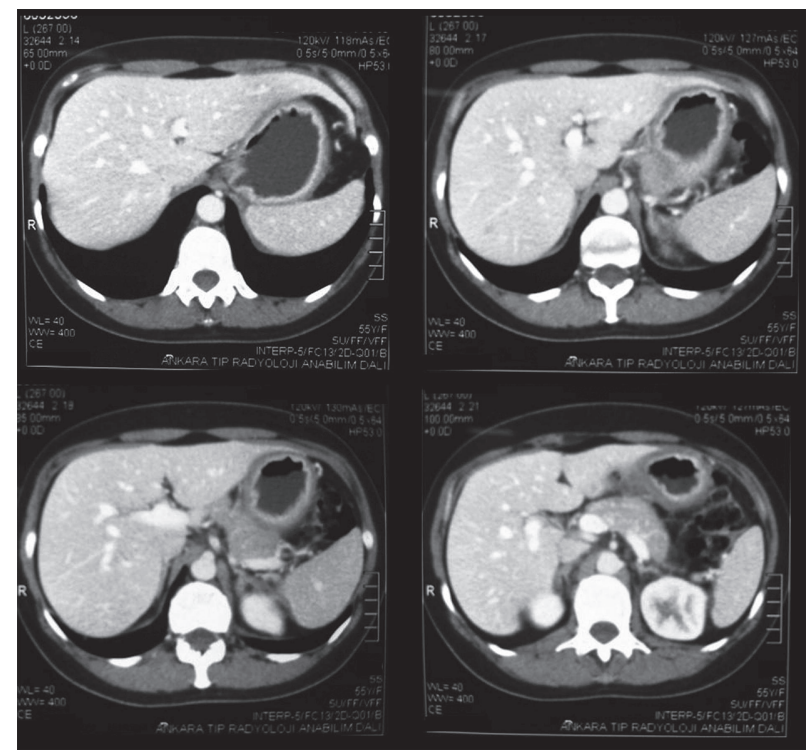

FIGURE 1: Computerized tomography image of 52-year-old patient. Gastric wall thickening of linitis plastica can be seen.
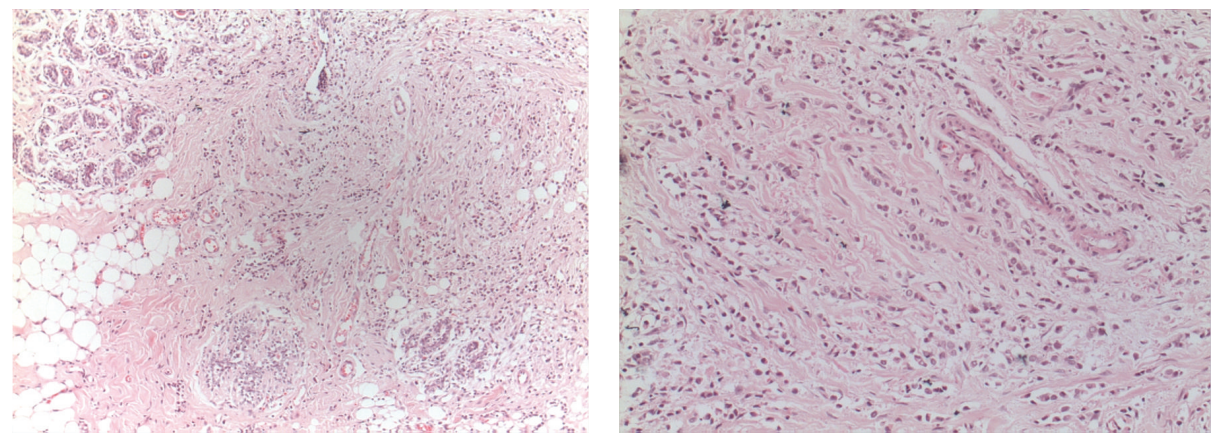

(a)
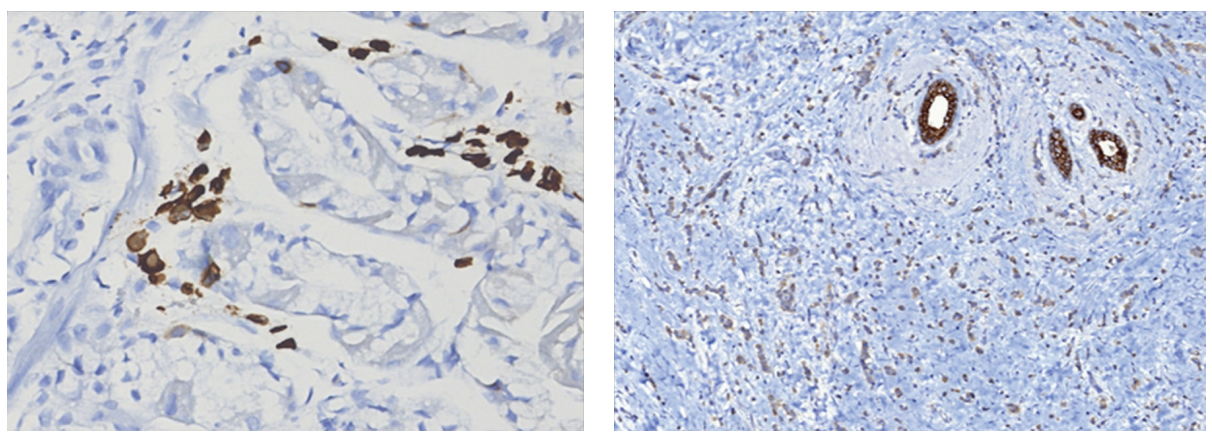

(b)

FiguRE 2: Histological images of ectopic breast tissue, gastric mucosa. (a) Left: tumor infiltration in ectopic breast tissue. H\&E $\times 10$. (a) Right: small noncohesive tumor cells individually dispersed or arranged in a single-file linear pattern in ectopic breast tissue. H\&E $\times 20$. (b) Left: GCDFP15 is focally positive in neoplastic cells. GCDFP15 $\times 40$. (b) Right: strong positivity seen in regular duct epithelium. Loss of staining in neoplastic cells. E-cadherin $\times 20$ (H\&E: Hematoxylin and Eosin).

lymph node metastasis from gastric cancer, the patient underwent excisional biopsy of the axillary mass. Histological examination showed invasive lobular carcinoma arising in ectopic breast tissue. The tumor was composed of noncohesive cells individually dispersed or infiltrating in a single-file linear pattern resembling "Indian files," within a fibrous stroma (Figure 2(a)). Immunohistochemical staining revealed the tumor cells to be diffusely strong positive for progesterone receptor (PR) and faintly positive for estrogen receptor (ER). As the morphological appearance strongly 


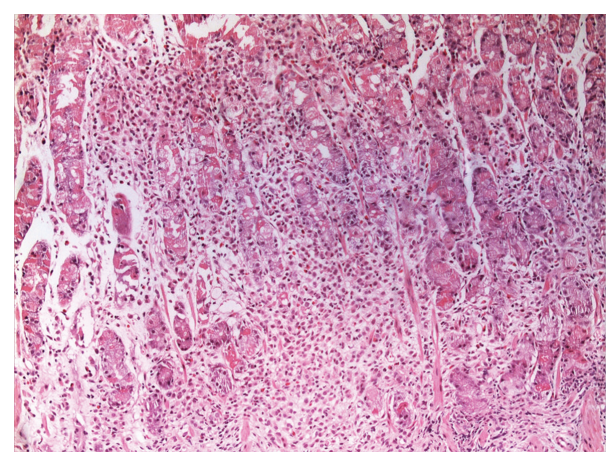

(a)

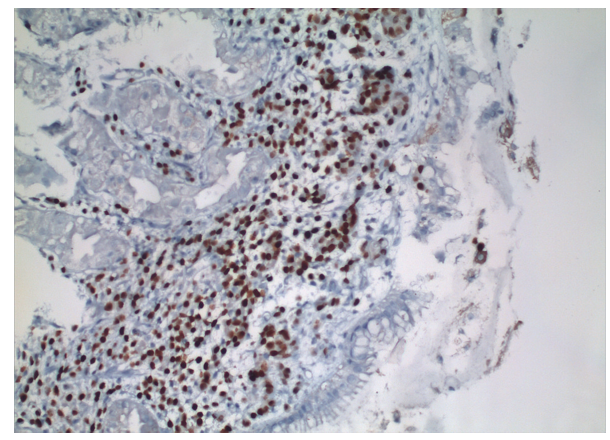

(b)

FIgURE 3: (a) Gastric mucosa infiltrated by cords of metastatic lobular carcinoma cells. $H \& E \times 10$. (b) Estrogen receptor positive tumor cells in gastric lamina propria. $\mathrm{H} \& \mathrm{E} \times 20$ (H\&E: Hematoxylin and Eosin).

indicated lobular carcinoma, E-cadherin and GCDFP-15 were studied. Strong E-cadherin positivity was seen in regular duct epithelium, and on the other hand, loss of staining was observed in neoplastic cells (Figure 2(b) (left)). Moreover GCDFP15 was focally positive in neoplastic cells (Figure 2(b) (right)). Endoscopy was repeated and submucosal biopsy samples were obtained. Histological examination showed atypical cells containing small, round, oval-shaped nucleoli with faintly eosinophilic or clear cytoplasm (Figure 3(a)). Immunohistochemical staining showed the tumor cells to be ER and PR positive (Figure 3(b)), cytokeratin (CK) 20 negative, and CK 7 intensely positive, which is consistent with metastatic lobular carcinoma. Bilateral mammography imaging was performed, demonstrating nodular dysplastic changes in fibroglandular tissue, nodular opacities superimposed with fibroglandular tissue and in the left breast upperouter quadrant, and conglomerated microcalcifications with low density. On breast ultrasonography, the upper-outer quadrants of both breasts were more intense. Hypoechoic multicentric solid lesions measuring $11 \times 10 \mathrm{~mm}$ and $7 \times 4 \mathrm{~mm}$ in the left breast and $12 \times 11 \mathrm{~mm}$ in the right breast were present. In the left axillary region, multiple lymph nodes with thick cortices measuring $15 \times 10 \mathrm{~mm}$ were seen. Ultrasonography guided large-core needle biopsy was performed for the lesions in the left breast. Histological examination showed no signs of malignancy. The patient was sent to the Medical Oncology Department in order to plan further treatment.
The patient is followed up for 12 months. No signs of malignancy in the left breast were observed in this period.

\section{Discussion}

Breast development begins in the 4th embryologic week. Milk lines originating from the ectoderm appear on the anterior abdominal wall in the 5th-6th embryological weeks and gradually regress, except in the pectoral area. When problems arise during the process of regression of the mammary fold in the embryological period, impairments in the number and location of the breasts are observed. While the presence of supernumerary nipples alone is called polythelia, the presence of supernumerary breast is called polymastia. Ectopic breast tissue that does not contain the nipple or areola, but only glandular breast tissue, is called aberrant breast tissue. Ectopic breast tissue cancers account for $0.3-0.6 \%$ of all breast cancers and generally originate from the axilla [4]. Otherwise, it may also be seen in the sternal area, subclavian region, infraclavicular region, xiphosternal junction, epigastrium, and labia majora. Ectopic breast cancer generally involves women aged above 40 years. While the male/female ratio is 0.01 for primary breast cancer, it is increased to 0.035 in ectopic breast cancer. All other risk factors seem to be similar to those of primary breast cancer [5]. Histologically, most adenocarcinomas arising in aberrant breast tissue have been of the ductal type. Other subtypes also have been described, including medullary, papillary, and lobular carcinomas. In ectopic breast cancer arising in the axilla, metastasis to the supraclavicular lymph nodes that ensures the lymphatic drainage of this region should be considered regional lymph node metastasis rather than distant metastasis. Contrarily, while internal mammary lymph node metastases are considered nodal metastases in primary breast cancer, they should be regarded as distant metastases in ectopic breast cancer arising in the axilla. Treatment consisting of locoregional surgery (local excision and axillary dissection) and radiotherapy is considered enough. Endocrine therapy and/or chemotherapy should be added [5].

The gastrointestinal tract is a rare site of metastasis. In a postmortem series of 1010 patients, 17 subjects had gastric metastases (1.7\%) and were most commonly from primary tumors such as breast cancer, lung cancer, and melanoma [6]. As seen in the case presented, gastric metastasis of breast cancer is manifested by nonspecific symptoms, such as dyspepsia, anorexia, and epigastric pain. Endoscopically and radiologically, it frequently mimics linitis plastica [7]. The typical finding is diffuse intramural infiltration of the gastric wall by the tumor cells. The most commonly observed metastatic breast cancer is invasive lobular carcinoma $[7,8]$. As seen in our case, endoscopic findings may not be helpful in the diagnosis. Although the lamina propria was later shown to be infiltrated, no signs of tumor were spotted in gastroscopy. Because the metastatic tumor is usually limited to the submucosa and seromuscular layer, $50 \%$ of the cases have normal endoscopic findings [9]. Unfortunately, due to the presence of signet ring cells, lobular carcinoma of the breast is commonly confused with diffuse adenocarcinoma 
of the stomach. Therefore, an immunohistochemical analysis is required for the differential diagnosis. Several studies have shown almost uniform negativity for ER in primary gastric carcinomas is commonly detected. In contrast, one study demonstrated that up to $28 \%$ of these tumors may be ER positive, with a focal weak-to-moderate staining intensity [10]. However, in our case, ER staining was strong and diffuse. ER alpha, which is a second generation antibody, may be helpful in the differential diagnosis [11]. ER negativity in the primary tumor may create serious challenges in the diagnosis. In this case, GCDFP-15 (gross cystic disease fluid protein15) may be a significant marker, useful in the diagnosis of metastatic breast cancer [12]. CK 20 is positive in gastric, colorectal, pancreatic, and transitional cell carcinomas, while it is not usually observed in any breast carcinomas [13]. In contrast, CK 7 is positive in $90 \%$ of breast carcinomas and also in 50-64\% of primary gastric adenocarcinomas $[14,15]$.

Consequently, CK 7 and CK 20 expression patterns are very useful in diagnosing metastatic carcinomas of uncertain origin. While approximately $30 \%$ of gastric adenocarcinomas are $\mathrm{CK} 7+/ \mathrm{CK} 20+, 20 \%$ are $\mathrm{CK} 7-/ \mathrm{CK} 20+, 10 \%$ are CK7-/CK20-, and 20\% are CK7+/CK20- [15]. Therefore, a panel of markers including ER, GCDFP-15, and CK 7/CK 20 may be used in the differential diagnosis of breast and gastric carcinoma in difficult cases. Gastric metastasis of breast cancer is considered to be a systemic disease. Anticancer chemotherapy and endocrine therapy are effective, but surgery has no effect on the prognosis. In the series by McLemore et al. [16], the mean survival time was 28 months. In our case, the follow-up period is about 24 months.

In conclusion, all kinds of diseases observed in primary breast tissue may also develop in ectopic breast tissue. Metastasis of ectopic breast cancer to the stomach, which is a rarely encountered metastatic site, is occasionally confused with primary gastric cancer. In our case, which is the first case of this kind in the literature, the initial presentation suggested the diagnosis of gastric cancer, but further examination revealed the accurate diagnosis of metastatic ectopic breast cancer.

\section{Consent}

The patient described in this report has signed an informed consent which is available upon request.

\section{Conflict of Interests}

The authors declare that there is no conflict of interests regarding the publication of this paper.

\section{Authors' Contribution}

Selami Ilgaz Kayılığlu (corresponding author) made a contribution to data collection, review of literatures, and drafting the paper; Cihangir Akyol to data collection, review of literatures, and the scientific revision of the paper; Ebru Esen to data collection and review of literatures; Cevriye CansizErsöz to data collection, review of literatures, and drafting the paper; Akın Fırat Kocaay to review of literatures and the scientific revision of the paper; Volkan Genç to data collection and the scientific revision of the paper; Illknur Kepenekçi to data collection and scientific revision of the paper; and Seher Demirer to scientific revision of the paper.

\section{References}

[1] S. Fracchioli, M. Puopolo, I. A. R. de La Longrais et al., "Primary "breast-like" cancer of the vulva: a case report and critical review of the literature," International Journal of Gynecological Cancer, vol. 16, no. 1, pp. 423-428, 2006.

[2] N. Paksoy, "Ectopic lesions as potential pitfalls in fine needle aspiration cytology: a report of 3 cases derived from the thyroid, endometrium and breast," Acta Cytologica, vol. 51, no. 2, pp. 222-226, 2007.

[3] F. Hara, S. Kiyoto, D. Takabatake et al., "Metastatic breast cancer to the stomach resembling early gastric cancer," Case Reports in Oncology, vol. 3, no. 2, pp. 142-147, 2010.

[4] J.-H. Cheong, B.-C. Lee, and K.-S. Lee, "Carcinoma of the axillary breast," Yonsei Medical Journal, vol. 40, no. 3, pp. 290293, 1999.

[5] G. Visconti, Y. Eltahir, R. J. Van Ginkel, J. Bart, and P. M. N. Werker, "Approach and management of primary ectopic breast carcinoma in the axilla: where are we? A comprehensive historical literature review," Journal of Plastic, Reconstructive and Aesthetic Surgery, vol. 64, no. 1, pp. el-e1l, 2011.

[6] L. S. Menuck and J. R. Amberg, "Metastatic disease involving the stomach," The American Journal of Digestive Diseases, vol. 20, no. 10, pp. 903-913, 1975.

[7] B. G. Taal, H. Peterse, and H. Boot, "Clinical presentation, endoscopic features, and treatment of gastric metastases from breast carcinoma," Cancer, vol. 89, no. 11, pp. 2214-2221, 2000.

[8] G. E. Jones, D. C. Strauss, M. J. Forshaw, H. Deere, U. Mahedeva, and R. C. Mason, "Breast cancer metastasis to the stomach may mimic primary gastric cancer: report of two cases and review of literature," World Journal of Surgical Oncology, vol. 5, article 75, 2007.

[9] G. Lorimier, C. Binelli, P. Burtin et al., "Metastatic gastric cancer arising from breast carcinoma: endoscopic ultrasonographic aspects," Endoscopy, vol. 30, no. 9, pp. 800-804, 1998.

[10] H. Yokozaki, N. Takekura, A. Takanashi, J. Tabuchi, R. Haruta, and E. Tahara, "Estrogen receptors in gastric adenocarcinoma: a retrospective immunohistochemical analysis," Virchows Archiv A, vol. 413, no. 4, pp. 297-302, 1988.

[11] M.-L. F. Van Velthuysen, B. G. Taal, J. J. M. van der Hoeven, and J. L. Peterse, "Expression of oestrogen receptor and loss of E-cadherin are diagnostic for gastric metastasis of breast carcinoma," Histopathology, vol. 46, no. 2, pp. 153-157, 2005.

[12] S. Y. Chia, A. A. Thike, P. Y. Cheok, and P. H. Tan, "Utility of mammaglobin and gross cystic disease fluid protein15 (GCDFP-15) in confirming a breast origin for recurrent tumors," Breast, vol. 19, no. 5, pp. 355-359, 2010.

[13] T. Tot, "Cytokeratins 20 and 7 as biomarkers: usefulness in discriminating primary from metastatic adenocarcinoma," European Journal of Cancer, vol. 38, no. 6, pp. 758-763, 2002.

[14] P. Chu, E. Wu, and L. M. Weiss, "Cytokeratin 7 and Cytokeratin 20 expression in epithelial neoplasms: a survey of 435 cases," Modern Pathology, vol. 13, no. 9, pp. 962-972, 2000. 
[15] N. S. Goldstein and J. F. Silverman, "Immunohistochemistry of the gastrointestinal tract," in Diagnostic Immunohistochemistry: Theranostic and Genomic Applications, D. J. Dabbs, Ed., pp. 500539, W.B. Saunders, Philadelphia, Pa, USA, 3rd edition, 2010.

[16] E. C. McLemore, B. A. Pockaj, C. Reynolds et al., "Breast cancer: presentation and intervention in women with gastrointestinal metastasis and carcinomatosis," Annals of Surgical Oncology, vol. 12, no. 11, pp. 886-894, 2005. 


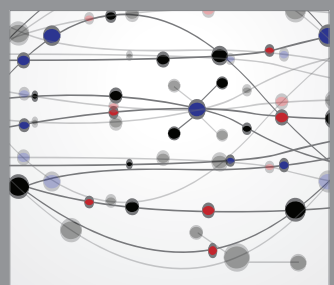

The Scientific World Journal
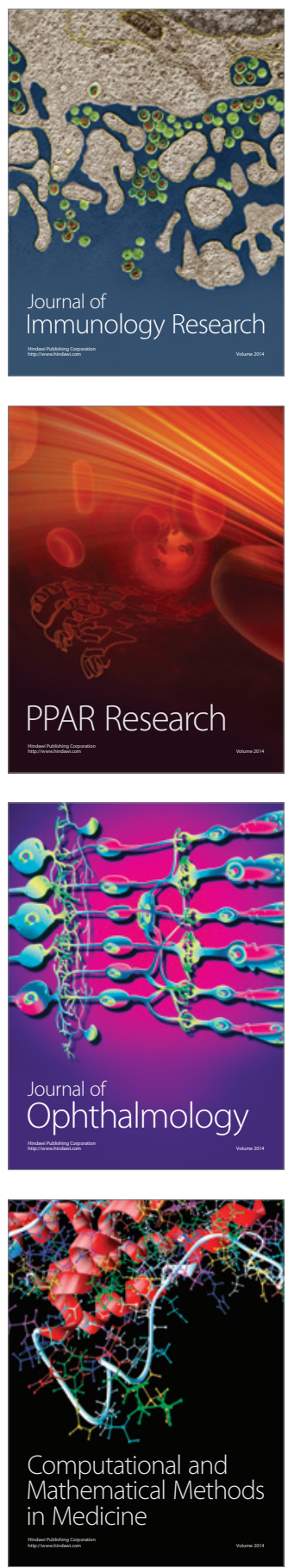

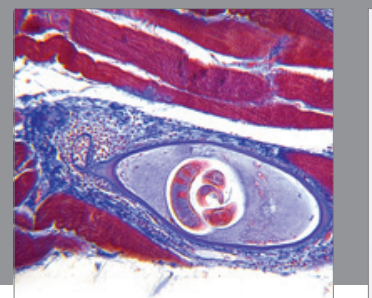

Gastroenterology

Research and Practice
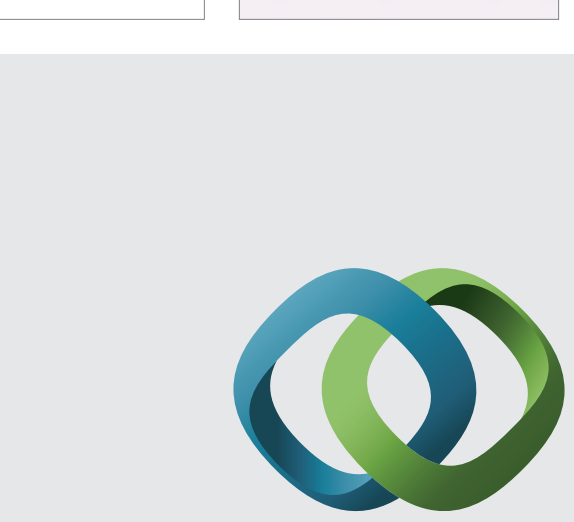

\section{Hindawi}

Submit your manuscripts at

http://www.hindawi.com
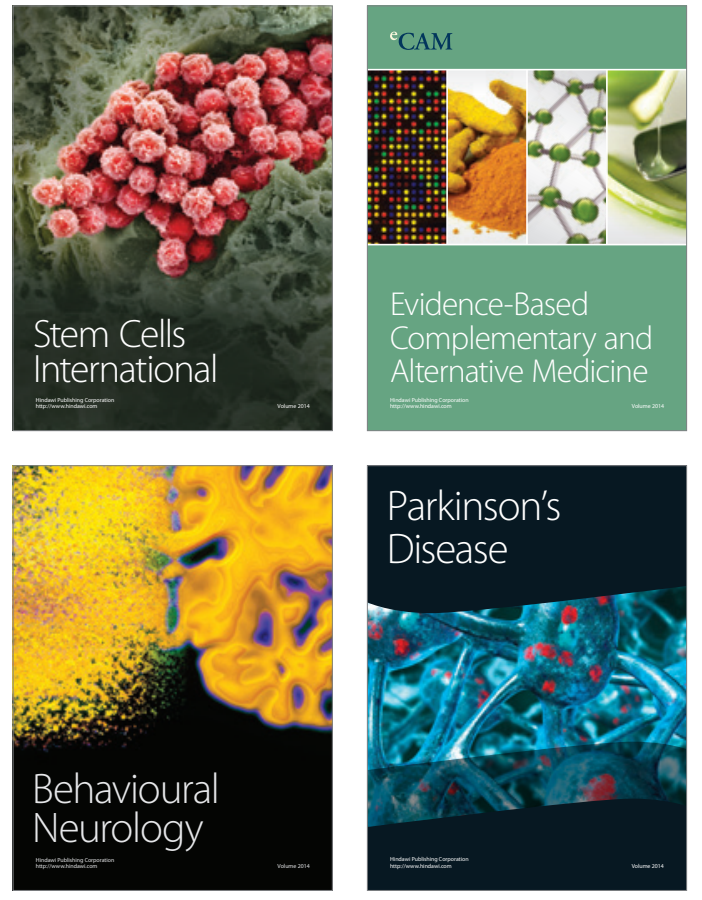
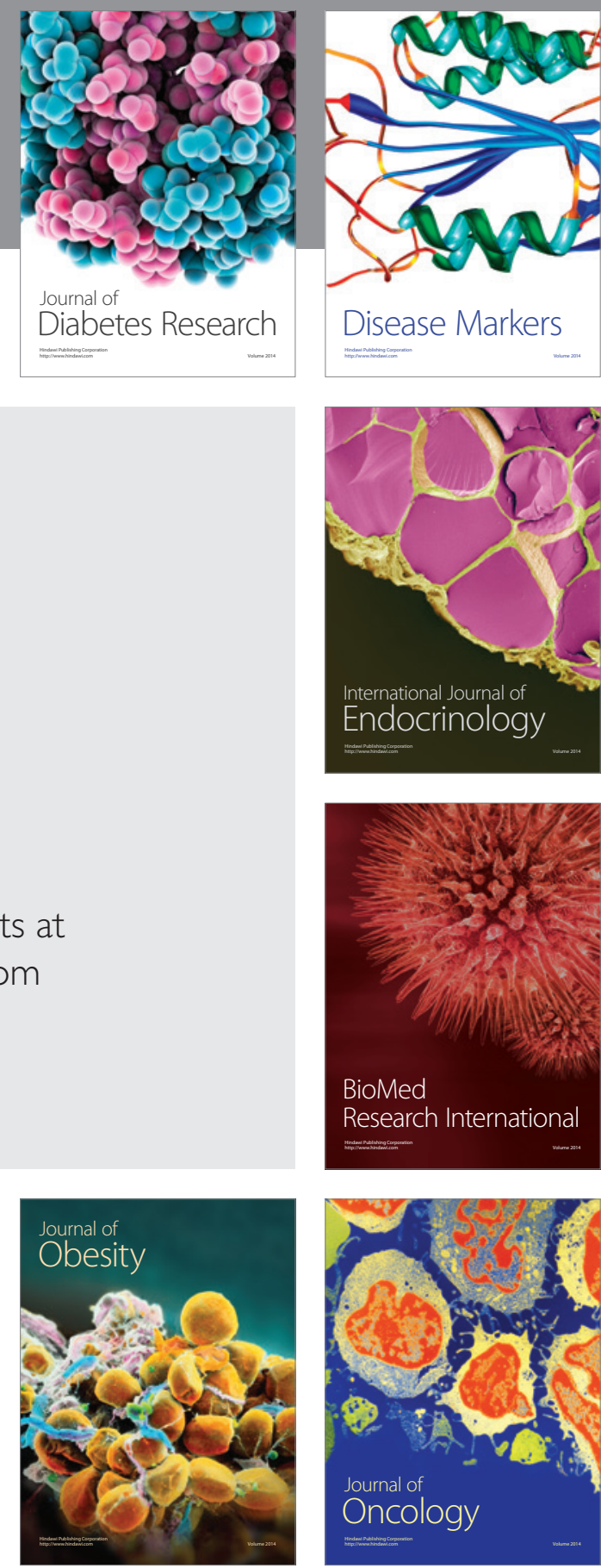

Disease Markers
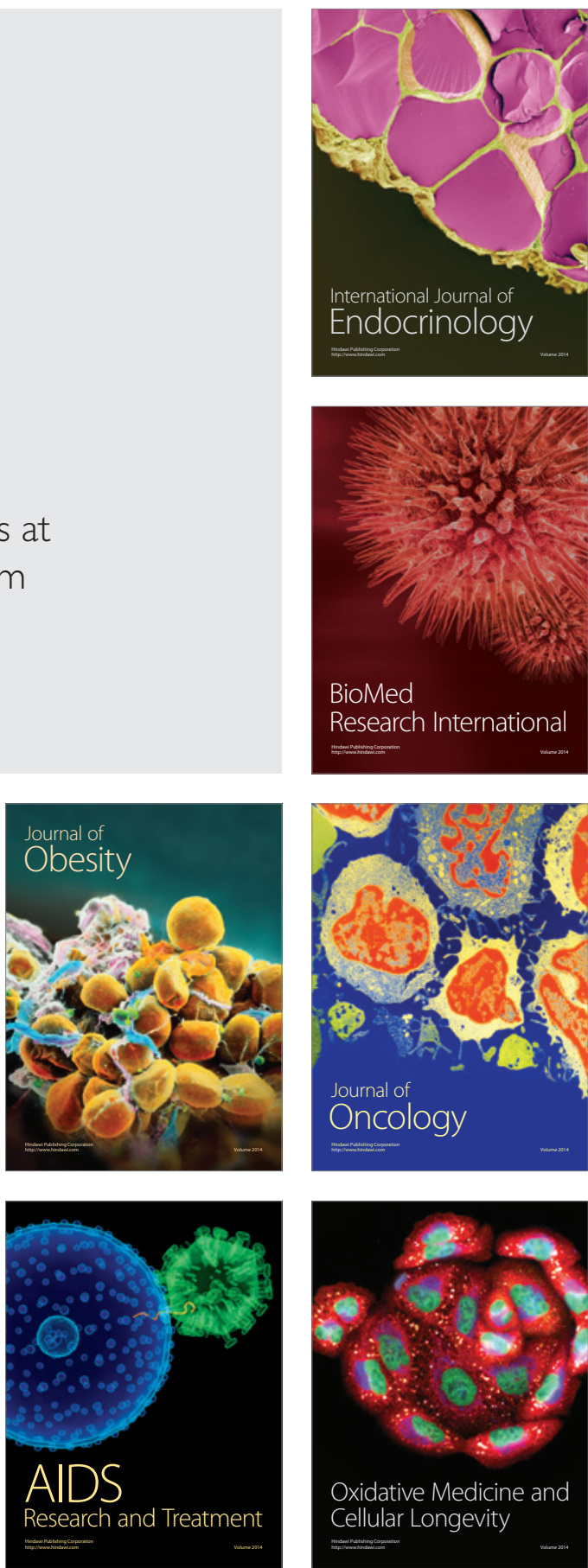